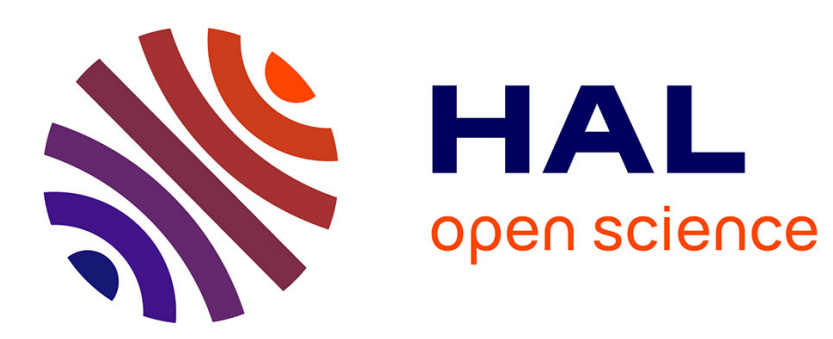

\title{
A comparison of the efficacy of cleaning and disinfection methods in eliminating Salmonella spp. from commercial egg laying houses
}

Juan Carrique-Mas, Clara Marin, Mark Breslin, Robert Davies, Ian Mclaren

\section{- To cite this version:}

Juan Carrique-Mas, Clara Marin, Mark Breslin, Robert Davies, Ian Mclaren. A comparison of the efficacy of cleaning and disinfection methods in eliminating Salmonella spp. from commercial egg laying houses. Avian Pathology, 2009, 38 (05), pp.419-424. 10.1080/03079450903193768 . hal00540165

\section{HAL Id: hal-00540165 \\ https://hal.science/hal-00540165}

Submitted on 26 Nov 2010

HAL is a multi-disciplinary open access archive for the deposit and dissemination of scientific research documents, whether they are published or not. The documents may come from teaching and research institutions in France or abroad, or from public or private research centers.
L'archive ouverte pluridisciplinaire HAL, est destinée au dépôt et à la diffusion de documents scientifiques de niveau recherche, publiés ou non, émanant des établissements d'enseignement et de recherche français ou étrangers, des laboratoires publics ou privés. 


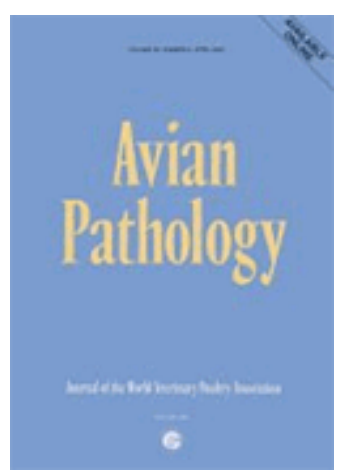

\section{A comparison of the efficacy of cleaning and disinfection methods in eliminating Salmonella spp. from commercial egg laying houses}

\begin{tabular}{|r|l|}
\hline Journal: & Avian Pathology \\
\hline Manuscript ID: & CAVP-2009-0053.R1 \\
\hline Manuscript Type: & Original Research Paper \\
\hline Date Submitted by the \\
Author: & 14 -Jul-2009 \\
\hline Complete List of Authors: & $\begin{array}{l}\text { Carrique-Mas, Juan; Veterinary Laboratories Agency, Food and } \\
\text { Environmental Safety } \\
\text { Marin, Clara; Instituto Valenciano de Investigaciones Agrarias } \\
\text { Breslin, Mark; VLA, FES } \\
\text { Davies, Robert; VLA, FES } \\
\text { McLaren, Ian; VLA, FES }\end{array}$ \\
\hline Keywords: & Salmonella, disinfection, layers, zoonosis \\
\hline
\end{tabular}

\section{SCHOLARONE" \\ Manuscripts}


A comparison of the efficacy of cleaning and disinfection methods in eliminating Salmonella spp. from commercial egg laying houses

Juan J Carrique-Mas ${ }^{1 *}$, Clara Marín ${ }^{2}$, Mark Breslin ${ }^{1}$, Ian McLaren ${ }^{1}$ and Rob Davies $^{1}$

${ }^{1}$ Department of Food and Environmental Safety, Veterinary Laboratories Agency, New Haw, Addlestone, KT15 3NB Surrey, United Kingdom, ${ }^{2}$ Centro de Tecnología Animal, Instituto Valenciano de Investigaciones Agrarias, Polígono La Esperanza, 12400 Segorbe, Spain

Running title: Cleaning and disinfection methods for Salmonella

Received: 2 April 2009

*To whom correspondence should be addressed. Tel: +44 1932357814 (Ext. 2814).

Fax: +44 1932 357595. Email: j.carrique-mas@ vla.defra.gsi.gov.uk 


\begin{abstract}
Effective terminal cleaning and disinfection $(C \& D)$ is regarded as a necessary step for the elimination of Salmonella spp. from laying houses. A total of 60 commercial laying houses which had housed laying flocks infected with Salmonella enterica serovar Enteritidis or Salmonella enterica serovar Typhimurium that were representative of all production systems (cage, barn, free-range) were intensively sampled immediately after C\&D as well as in the follow-on flock. The procedures investigated were: (1) A compound disinfectant consisting of a mixture of formaldehyde, glutaraldehyde and quarternary ammonium applied at the recommended concentration; (2) A $10 \%$ ( $\mathrm{vol} / \mathrm{vol}$ ) dilution of the standard $37 \%$ commercial formalin, applied by a contractor; (3) Other disinfection procedures selected and applied by the farmer. The recovery of Salmonella in the cleaned and disinfected houses was variable, with samples from floor and dropping boards/belts (cage houses) and scratching areas (non-cage houses) being the most likely to remain contaminated. In cage houses, the use of the $10 \%$ formalin dilution led to a statistically greater reduction in the sample prevalence than using any of the other C\&D method. A negative post-C\&D result predicted clearance of Salmonella in 52\% cases, although the isolation of Salmonella from the houses immediately after C\&D was not a perfect predictor of carry-over of infection.
\end{abstract}

\title{
Introduction
}

Salmonella infection is one of the most common causes of infectious gastroenteritis in humans worldwide (WHO, 2005). In the European Union (EU), Salmonella enterica serovar Enteritidis is the agent most frequently involved in human salmonellosis and it is also the serovar most widespread in egg production, followed at a distance by $S$. enterica serovar Typhimurium (Anonymous, 2006).

Eggs are regarded as the main source of infection of Salmonella Enteritidis for humans (Gillespie et al., 2005; de Jong \& Ekdahl, 2006). Over the last few years, the egg industry has stepped up its efforts to control Salmonella in laying houses. These have mostly involved an upgrade of biosecurity and hygiene procedures. In the United 
Kingdom (UK) and other countries vaccination with attenuated, live or killed vaccines is also now widespread among commercial laying flocks.

Despite this effective interventions to control Salmonella infection during the life of the flocks are limited, and effective terminal cleaning and disinfection (C\&D) is regarded as a crucial step to reduce the risk of infection to new flocks placed in houses that have held infected birds (van de Giessen et al., 1994).

In the UK, carry-over of SE between consecutive laying flocks has been shown to be a common occurrence (Carrique-Mas et al., 2008b; Carrique-Mas et al., 2008c; Wales, Breslin \& Davies, 2006b), which was concomitant with a generally low standard of C\&D, although the presence of rodents has also been described to be a major factor contributing to carry-over (Carrique-Mas et al., 2008b). C\&D is a costly and laborious task, and its success in eliminating Salmonella from the houses depends on the attention to detail, as well as on the choice and correct application of disinfectants (Davies \& Wray, 1995; Wales et al., Davies, 2006a). There is a wide range of disinfectant formulations available in the market, but there are marked differences in their efficacy (McDonnell \& Russell, 1999). Furthermore the efficacy of a disinfectant in the field is highly dependent on the level of residual organic matter remaining on the house surfaces. Because of their design, $C \& D$ of cage laying houses, is known to be particularly problematic (Davies \& Breslin, 2003; Wales et al., 2006a). Aldehydes are generally more effective than other disinfectants in poultry houses (Rose et al., 2000; Wales et al., 2006a) and where formaldehyde has been investigated, it has performed better than any other product, both in laboratory models using artificially inoculated surfaces (Gradel et al., 2004) and in field conditions (Davies et al., 1995). Historically C\&D has typically been carried out in the same manner over subsequent production cycles, irrespective of the Salmonella status of the laying houses. However the introduction in 2009 of Salmonella legislation across the EU (enacted by National Control Programmes) banning the sale of fresh eggs from $S$. Enteritidis or $S$. Typhimurium-positive flocks (EC No. 1237/2007) is likely to alter this situation, and more effective disinfection procedures will be sought by farmers with Salmonella positive flocks.

The aim of this study was to determine the comparative effectiveness of disinfection programmes in Salmonella-positive cage and non cage (i.e. free-range, barn) houses in the field, in particular an intensive method using $10 \%$ formalin applied with a pressure washer by a specialist contractor. 


\section{Materials and Methods}

Farms, laying houses and disinfection procedures. A total of 60 post C\&D visits to houses where either $S$. Enteritidis or $S$. Typhimurium had been isolated were carried out on 47 different laying houses in 23 different farms (sites) between February 2003 and September 2008. Prior to disinfection, houses were washed using a pressure washer and allowed to dry. The disinfection procedures investigated were: (1) A 10\% (vol/vol) formalin dilution of the standard 37\% commercial dilution, applied by a specialist contractor (Elebert Pestforce, Lymm, UK) using a high pressure washer to run-off point; (2) A formaldehyde, glutaraldehyde quaternary ammonium (F.G.Q.) compound (Superkill@, AFS Animal Care, Thetford, UK) applied at 'General Orders' (G.O.) rate (1:22) (DEFRA, 2009). The G.O. rate is the minimum concentration recommended by Defra (Department for Environment, Food and Rural Affairs of the United Kingdom), based on an in vitro suspension approval test. The disinfectant was applied by the farmer by power or pressure washer to run-off point; (3) 'In house' procedures: other disinfection procedures that were routinely used by the producers (Table 1). In all cases the disinfectants were applied to all surfaces of the house and anteroom (where present). Houses were restocked 1-3 days after the disinfectants had dried out from the house surfaces.

Sampling for Salmonella to assess the effectiveness of C\&D. The effectiveness of the $C \& D$ procedure was assessed by the culture of hand-held gauze swabs impregnated with buffered peptone water (BPW) that were used to wipe a range of surfaces in the house, before they were placed back into jars containing $225 \mathrm{ml}$ BPW (Davies et al., 2003; Wales et al., 2006a; Carrique-Mas et al., 2008c). For cage houses, 10 samples from each of the following areas were collected: (1) Cage interiors (eight cages per swab); (2) Drinker cups/troughs (eight per swab); (3) Feed troughs $\left(0.5 \mathrm{~m}^{2}\right.$ per swab); (4) Droppings boards/belts/flaps ( $1 \mathrm{~m}^{2}$ per swab); (5) House floor $\left(0.5 \mathrm{~m}^{2}\right.$ per swab); (6) Egg belts $\left(0.5 \mathrm{~m}^{2}\right.$ per swab). From non-cage houses, samples were collected from: (1) Drinkers (four bell drinkers per swab); (2) Feeders $\left(0.5 \mathrm{~m}^{2}\right.$ per swab); (3) Scratching area (if present) $\left(1 \mathrm{~m}^{2}\right.$ per swab); (4) Slats $\left(0.5 \mathrm{~m}^{2}\right.$ per swab); (5) Nest box interiors (five per swab). In addition, in free-range houses, the 
soil from the paddocks was sampled by scraping off $25 \mathrm{~g}$ of the topsoil which were added to the 225ml BPW jars (Davies et al., 2003). For each sampling visit and sample type, a prevalence of positive samples was calculated.

Sampling of flocks in lay. For each house investigated, laying flocks before and after terminal C\&D were sampled in an identical way. Dust and faeces were collected from the occupied houses from flocks in lay placed before disinfection and of the first flock after restocking. For this, 10 pooled faeces $(25 \mathrm{~g})$ and 10 dust samples $(15 \mathrm{~g})$ were collected from each flock directly into $225 \mathrm{ml}$ BPW pots using large gauze swabs. This is regarded as a very sensitive sampling method (Carrique-Mas et al., 2008a).

Bacteriological methods. Samples in BPW were cultured following a simplified protocol of ISO 6579:2002 (Annex D) consisting of pre-enrichment in BPW followed by enrichment in modified semi-solid Rappaport Vassiliadis_MSRV) medium and plating onto Rambach agar (Wales et al., 2006a). Suspect Salmonella colonies were confirmed by serotyping using the Kauffmann-White typing scheme.

Statistical analyses. The level of contamination of flocks before and after C\&D was estimated by calculating an average (weighted) percentage of faeces and dust samples positive. Chi-square tests were used to assess differences in proportions and the (nonparametric) Wilcoxon test statistic was used to compare the sample prevalence before and after the disinfection. All analyses were carried out using S-Plus (Insight, USA).

\section{Results}

Post C\&D sampling visit. All houses sampled after C\&D had previously contained flocks positive for SE, except one case where STM was present. A total of 1080, 1140, and 660 samples (combined data) were collected for houses treated with the in house', F.G.Q (G.O rate), and 10\% formalin C\&D programmes, respectively. The total prevalence of positive samples was $31.5 \%, 9.0 \%$, and $3.3 \%$, respectively. For cage houses, sample prevalence was (from highest to lowest): floors (24.8\%), dropping boards/belts/flaps (22.7\%), drinkers (15.2\%), feeders (13.8\%), cage interiors $(11.4 \%)$ and egg belts $(9.4 \%)$. A comparable proportion of positive samples were 
recovered from floor and dropping board samples $\left(\chi^{2}=0.35 ; \mathrm{p}=0.55\right)$, and the proportion of positive samples from both were significantly greater than that obtained from any other type of sample $(\mathrm{p}<0.05)$. In non-cage houses, the highest sample prevalence was in scratching areas $(32.6 \%)$, drinkers $(7.5 \%)$, feeders $(5.7 \%)$, nest boxes $(3.3 \%)$ and slats $(2.7 \%)$. The proportion of positive samples from scratching areas were greater than any other type of sample $(\mathrm{p}<0.008) .35 .7 \%$ soil samples from the paddocks tested positive. The mean sample prevalence by disinfection type is presented in Table 2, and the median prevalence of positive samples by sample type and disinfection method is shown in Figures 1 and 2. Results for non-cage houses treated using the formalin $10 \%$ method are not shown given that only two houses were examined.

Level of infection in flocks before treatment. Flocks in cage houses sampled in lay before the C\&D had a median (dust and faeces weighted) sample prevalence of $39.7 \%$ [IQR 15.3\%-65.2\%], and in non-cage houses the median (dust and faeces weighted) sample prevalence was $48.4 \%$ [IQR 28.6\%-71.2\%]. These differences were not statistically significant (Wilcoxon $\mathrm{Z}=-0.75 ; \mathrm{p}=0.454$ ). Flocks in houses that were later treated using the 'in-house' method had a significantly higher level of infection (63.2\% [IQR 41.4-81.2]) than those treated with formalin (44.3\% [20.7-65.9]) (Wilcoxon $\mathrm{Z}=2.0$; $\mathrm{p}=0.045$ ) or F.G.Q. (G.O.) (25.9\% [13.7-43.9]) (Wilcoxon $\mathrm{Z}=3.54$; $\mathrm{p}<0.001)$. The percent of cases where the follow-on flock was Salmonella-free (i.e. Salmonella was eliminated from the building) was 7/13 (54\%), 8/23 (35\%) and 5/24 (21\%) for houses treated with formalin 10\%, F.G.Q. (G.O.) and the in-house method, respectively.

\section{Comparison of the efficacy of each treatment on the levels of infection of follow-}

on flock. The level of infection of the follow-on flocks, as judged from the percentage of samples which were positive, increased in 6/18 (33.3\%), 3/19 (15.8\%) and 0/11 $(0 \%)$ of cases using the 'in-house' method, F.G.Q. (G.O.), and formalin $10 \%$ respectively. In all remaining cases, there was a reduction of the levels of infection of the follow-on flock. This included all non-cage houses regardless of the treatment (Figure 3). The variation in the prevalence of positive samples from the laying flocks before and after C\&D is presented in Table 3. The median observed reductions were $71.0 \%$ [(interquartile range (IQR) -95.9 to -14.2 ] and $-97.3 \%$ [IQR -100 to -79.4 ] for 
cage and non-cage houses, respectively $(Z=2.10, \mathrm{p}=0.035)$. Overall, a significantly greater reduction was observed only with formalin $10 \%$, compared with the in-house programme $(Z=-2.64, p=0.008)$. In cage houses, the $10 \%$ formalin dilution method performed better than the F.G.Q $(\mathrm{Z}=-2.13, \mathrm{p}=0.033)$ and the 'in house' method $(\mathrm{Z}=-$ 3.41, p<0.001). In non-cage houses, the F.G.Q method performed better than the in house' method, but the difference was only borderline significant $(\mathrm{Z}=-1.80, \mathrm{p}=0.07)$. No statistical comparisons with the $10 \%$ formalin dilution method were attempted in non-cage houses due to the small number of houses treated with formalin $(n=2)$.

Significance of post-C\&D sampling results. A negative post C\&D sampling result resulted in a Salmonella-negative follow-on flock in 57\% of cases (Table 4). There was a linear trend towards an increased risk in carry-over for houses with higher levels of Salmonella after cleaning and disinfection $\left(\chi^{2}\right.$ for linear trend 8.57; $\mathrm{p}=0.0031$ ), although houses with a negative $C \& D$ result still had a $43 \%$ probability of carry-over.

In the case of free-range houses, there was evidence of contamination in the soil of the paddocks at the time of the post C\&D visit in 6/9 cases. None of the follow-on flocks placed in the three houses with negative paddocks tested positive, compared with $4 / 6$ of those with evidence of contamination of the paddocks.

\section{Discussion}

The perpetuation of SE infection in laying flocks is commonly related to the presence of a contaminated house environment (van de Giessen et al., 1994; Wales et al., 2007; Carrique-Mas et al., 2008c). Therefore adequate cleaning and disinfection is regarded as a crucial step in eliminating infection from the houses. The present study demonstrated the variable impact of different cleaning and disinfection regimes on Salmonella-positive laying houses. An ideal study design to investigate this in the field would be a randomised controlled trial with assessment of compliance but this was not possible because of cost issues. Therefore, we need to accept the limitations and possible biases of this descriptive study.

The best results were achieved using $10 \%$ formalin applied by a specialist contractor and the second best results were obtained using a blended disinfectant 
which also contained formaldehyde, in combination with glutaraldehyde and quarternary ammonium compounds. Other disinfection methods did not perform as well, although the diversity of treatments does not permit conclusions regarding any particular product to be made. The efficacy of the application of the $10 \%$ formalin treatment by spray was reflected not only in the lower recovery of Salmonella from the treated surfaces in the house, but in lower rate of infected follow-on flocks and a reduction in the levels of infection in houses where an infected flock was present. It is important to emphasize that this is different from the application of formalin by fogging, a less intensive treatment which is common in the poultry industry. Fogging is regarded as not very efficient on its own due to the considerable shadowing effect associated with the complicated structures of the house. For health and safety reasons, it is better that formalin is by a specialist contractor. This is likely to represent an additional expense, which may largely be compensated by the improved performance of this disinfection method and improved health and production in the subsequent flocks.

There is potentially a source of bias in the study resulting from the uneven distribution of the level of contamination in the houses investigated by type of treatment, since the allocation of C\&D treatments was not under our control. The houses that were treated with the 'in-house' method had also contained flocks with the overall highest levels of infection. However flocks that were treated with formalin had a greater initial level of infection than those treated with the F.G.Q. product, and even so, the disinfection effect was greater using the $10 \%$ formalin dilution. In one of the two non-cage houses (a barn) the formalin treatment did not succeed. This was the first house to be treated in the study. The reason for this failure was a very poor standard of cleaning before the application of the disinfectant, being particularly bad in nest boxes and drinker cups, which where largely missed by the cleaning team. In addition the house was quickly re-contaminated by mouse faeces.

Laying houses are notoriously difficult to clean thoroughly because of their intrinsically complicated structures, which are even more complex in the case of cage laying houses (Wales et al., 2006a). Access to cage interiors, feeders, egg belts, etc is very difficult unless a great deal of effort and time is invested. It seems that in these circumstances a large amount of residual organic matter is expected after a standard disinfection procedure. Our results are consistent with previous results where formalin has also shown to perform better than any other disinfectant. This has been confirmed 
using laboratory models using Salmonella-spiked surfaces (Berchieri \& Barrow, 1996; Gradel et al., 2004) but also in field studies (Davies et al., 1995; Rose et al., 2000; Davies et al., 2003).

The general trend in the houses investigated was a reduction of the levels of infection of the follow-on flocks regardless of the treatment used, although there was a poor predictive value of a negative C\&D result. Only in $42 \%$ of cases where a negative post $C \& D$ result was obtained was there evidence of clearance of infection of the follow-on flock. This is likely to be a consequence of the presence of other major sources of infection to the flocks, notably rodents (Carrique-Mas et al., 2008b). Likewise, a positive result after C\&D, particularly at a low level, does not necessarily lead to infection of the new flock, as has been reported previously (Davies \& Wray, 1996). It is possible in some cases that our involvement in the study may also have lead to a more pro-active attitude by the farmer in terms of upgraded rodent control and biosecurity measures. In houses where relatively small numbers of rodents were present an upgrade of baiting procedures may have been sufficient to reduce the challenge to the newly placed flocks.

An important observation in this study is the widespread lack of knowledge by the farmers of the appropriate concentrations of disinfectants. In the UK, activity against Salmonella is evaluated and the efficacy reported in the 'General Orders' concentration. The main confusion arising for the use disinfectants appears to be related to their reconstitution at a lower than optimal concentration, as it is recommended for other uses. It would be preferable if a suitable concentration for disinfection of Salmonella in biofilms on soiled surfaces could be defined for all products so that operators can obtain clear guidance on appropriate disinfection.

Paddocks adjacent to free-range houses are rarely included in the cleaning and disinfection programme. Although in many cases paddocks have been reported to carry Salmonella, they are considered to be less of a risk for birds than residual contamination in the house, since carry-over has been rare provided that the house has been correctly disinfected (Davies et al., 2003).

The current results are particularly relevant in the context of the enforcement of restriction on the sale of fresh eggs from flocks infected with $S$. Enteritidis and/or $S$. Typhimurium. The present study provides evidence that the use of the $10 \%$ formalin dilution is particularly useful in the decontamination of infected cage laying 
flocks, although in most cases this intervention has to be concomitant with rodent control to reduce the chances of carry-over of infection.

\section{Acknowledgements}

The authors wish to thank all participating farmers for their support. This work was funded through the Department for Environment, Food and Rural Affairs of the Government of the United Kingdom (Project OZ0325). We are also grateful to Dr. Sarah Evans for comments and improvements to the original manuscript.

\section{References}

Anonymous (2006). Reducing Salmonella in European egg-laying hens: EU targets now set. Eurosurveillance, 11, E060810 3.

Berchieri, A., Jr. \& Barrow, P.A. (1996). The antibacterial effects for Salmonella Enteritidis phage type 4 of different chemical disinfectants and cleaning agents tested under different conditions. Avian Pathology, 25, 663-73.

Carrique-Mas, J.J., Breslin, M., Sayers, A.R., McLaren, I., Arnold, M. \& Davies, R. (2008a). Comparison of environmental sampling methods for detecting Salmonella in commercial laying flocks in the UK. Letters in Applied Microbiology, 47, 514-9.

Carrique-Mas, J.J., Breslin, M., Snow, L., McLaren, I., Sayers, A.R. \& Davies, R.H. (2008b). Persistence and clearance of different Salmonella serovars in buildings housing laying hens. Epidemiology and Infection, 137, 837-46.

Carrique-Mas, J.J., Breslin, M., Snow, L., Arnold, M.E., Wales, A., McLaren, I. \& Davies, R.H. (2008c). Observations related to the Salmonella EU layer baseline survey in the UK: Follow-up of positive flocks and sensitivity issues. Epidemiology and Infection, 47, 514-19. 
Davies, R.H. \& Wray, C. (1995). Observations on disinfection regimens used on Salmonella enteritidis infected poultry units. Poultry Science, 74, 638-647.

Davies, R.H. \& Wray, C. (1996). Persistence of Salmonella enteritidis in poultry units and poultry food. British Poultry Science, 37, 589-96.

Davies, R. \& Breslin, M. (2003). Observations on Salmonella contamination of commercial laying farms before and after cleaning and disinfection. Veterinary Record, 152, 283-7.

De Jong, B. \& Ekdahl, K. (2006). Human salmonellosis in travellers is highly correlated to the prevalence of Salmonella in laying hen flocks. Eurosurveillance, 11, E060706 1.

DEFRA (2009). Disinfectants Approved for use in England and Wales. Available online:

http://disinfectants.defra.gov.uk/Default.aspx?Location=None\&module=Appr ovalsList_SI (Accessed 9 October 2008).

Gillespie, I.A., O'Brien, S.J., Adak, G.K., Ward, L.R. \& Smith, H.R. (2005). Foodborne general outbreaks of Salmonella Enteritidis phage type 4 infection, England and Wales, 1992-2002: where are the risks? Epidemiology and Infection, 133, 795-801.

Gradel, K.O., Sayers, A.R. \& Davies, R.H. (2004). Surface disinfection tests with Salmonella and a putative indicator bacterium, mimicking worst-case scenarios in poultry houses. Poultry Science, 83, 1636-1643.

McDonnell, G. \& Russell, A.D. (1999). Antiseptics and disinfectants: activity, action, and resistance. Clinical Microbiology Reviews, 12, 147-179. 
Rose, N., Beaudeau, F., Drouin, P., Toux, J.Y., Rose, V. \& Colin, P. (2000). Risk factors for Salmonella persistence after cleansing and disinfection in French broiler-chicken houses. Preventive Veterinary Medicine, 44, 9-20.

Van de Giessen, A.W., Ament, A.J. \& Notermans, S.H. (1994). Intervention strategies for Salmonella enteritidis in poultry flocks: a basic approach. International Journal of Food Microbiology, 21, 145-54.

Wales, A., Breslin, M., Carter, B., Sayers, R. \& Davies, R. (2007). A longitudinal study of environmental Salmonella contamination in caged and free-range layer flocks. Avian Pathology, 36, 187-197.

Wales, A., Breslin, M. \& Davies, R. (2006a). Assessment of cleaning and disinfection in Salmonella-contaminated poultry layer houses using qualitative and semiquantitative culture techniques. Veterinary Microbiology, 116, 283-93.

Wales, A., Breslin, M. \& Davies, R. (2006b). Semiquantitative assessment of the distribution of Salmonella in the environment of caged layer flocks. Journal of Applied Microbiology, 101, 309-18.

WHO (2005) Drug-resistant Salmonella. Factsheet No. 139. Available on-line: http://www.who.int/mediacentre/factsheets/fs139/en/ (Accessed 5 November 2008). 
Table 1. Number of laying houses investigated by type of production and disinfection procedure

\begin{tabular}{|c|c|c|c|}
\hline & Cage & Non-cage & All \\
\hline 'In-house' method & 18 & 6 & 24 \\
\hline \multirow{2}{*}{$\begin{array}{r}\text { F.G.Q. disinfectant (applied at a lower } \\
\text { dilution than the G.O. rate) }\end{array}$} & 7 & 2 & 9 \\
\hline & & & \\
\hline Peroxygen-based disinfectant & 6 & 2 & 8 \\
\hline Non Defra-approved disinfectant & 2 & 0 & 2 \\
\hline ed & 3 & 2 & 5 \\
\hline F.G.Q. (at G.O. rate) & 19 & 4 & 23 \\
\hline Formalin $10 \%$ & 11 & 2 & 13 \\
\hline Total & 48 & 12 & 60 \\
\hline
\end{tabular}


Table 2. Mean (and 95\% CI) Salmonella-positive sample prevalence by sample type

\begin{tabular}{rcccccc}
\hline & \multicolumn{2}{c}{ 'In-house' } & \multicolumn{2}{c}{ F.G.Q. (G.O. rate) } & \multicolumn{2}{c}{ Formalin 10\% } \\
\cline { 2 - 7 } \% positive & $95 \%$ CI & \% positive & $\%$ positive & 95\% CI & \% positive \\
\hline $\begin{array}{r}\text { Cage houses } \\
\text { Cage interior }\end{array}$ & 22.9 & $16.8-29.0$ & 4.8 & $1.7-8.0$ & 1.8 & $0.0-4.3$ \\
Drinkers & 26.0 & $19.6-32.3$ & 12.5 & $7.7-17.4$ & 1.8 & $0.0-4.3$ \\
Feeders & 26.6 & $20.0-33.3$ & 8.1 & $4.2-12.0$ & 3.6 & $0.1-7.1$ \\
Dropping boards & 44.9 & $37.2-52.6$ & 10.3 & $5.4-15.2$ & 6.4 & $1.8-10.9$ \\
Egg belts & 21.4 & $15.2-27.6$ & 3.9 & $1.2-6.7$ & 1.8 & $0.0-4.3$ \\
Floor & 47.0 & $39.3-55.3$ & 15.5 & $10.1-21.0$ & 3.6 & $0.1-7.1$
\end{tabular}

Non-cage houses

$\begin{array}{rrrrrrr}\text { Nest boxes } & 1.7 & 0.0-4.9 & 0.0 & \text { N.C. } & 15 & 0.0-30.6 \\ \text { Drinkers } & 5.0 & 0.0-10.5 & 0.0 & \text { N.C. } & 30 & 9.9-50.1 \\ \text { Feeders } & 9.5 & 2.0-16.9 & 0.0 & \text { N.C. } & 0.0 & \text { N.C. } \\ \text { Slats } & 3.3 & 0.0-7.9 & 3.3 & 0-10.0 & 0.0 & \text { N.C. } \\ \text { Scratching } & 43.5 & 30.1-56.0 & 0.0 & \text { N.C. } & 0.0 & \text { N.C. } \\ \text { Soil (range) }\end{array}$

N.C. $=$ not calculated 
Table 3. Change in the sample prevalence between flock 1 (prior to treatment) and flock 2 (after treatment)

\begin{tabular}{lccc}
\hline Type of house & Method & $\begin{array}{c}\text { Median } \\
\text { difference }\end{array}$ & 75\% IQR \\
\hline \multirow{2}{*}{ Cage } & 'In-house' & -47.2 & $-72.6-3.92$ \\
& F.G.Q. & -70.0 & $-98.9--14.1$ \\
Non-cage & Formalin & -92.7 & $-100--85.4$ \\
& 'In-house' & -91.9 & $-98.6--59.8$ \\
& F.G.Q. & -100 & $-100--100$ \\
& Formalin & -74.0 & $-53.7--33.4$ \\
\hline
\end{tabular}

$\mathrm{IQR}=$ Inter-quartile range 
Table 4. Relationship between post $C \& D$ sampling results and follow-on flock

\begin{tabular}{rccc}
\hline & \multicolumn{3}{c}{ Follow-on flock Salmonella status } \\
\cline { 2 - 4 } \% Positive samples & Positive & Total & $\begin{array}{c}\text { \% Salmonella } \\
\text { positive }\end{array}$ \\
\hline Negative & 6 & 14 & 42.9 \\
$>0 \%-5 \%$ & 8 & 14 & 57.1 \\
$>5 \%-11.3 \%$ & 8 & 9 & 88.9 \\
$>11.3 \%-25 \%$ & 11 & 12 & 91.7 \\
$>25 \%$ & 10 & 11 & 90.9 \\
\hline
\end{tabular}


Figure 1. Results of the $C \& D$ procedure of cage houses using three disinfection methods: an 'in-house' method $(N=18)$, formaldehyde/glutaraldehyde/quarternary ammonium (F.G.Q.) at General Orders $(G . O)$ rate $(N=19)$ and using $10 \%$ formalin dilution $(N=11)$.

'In-house' disinfection

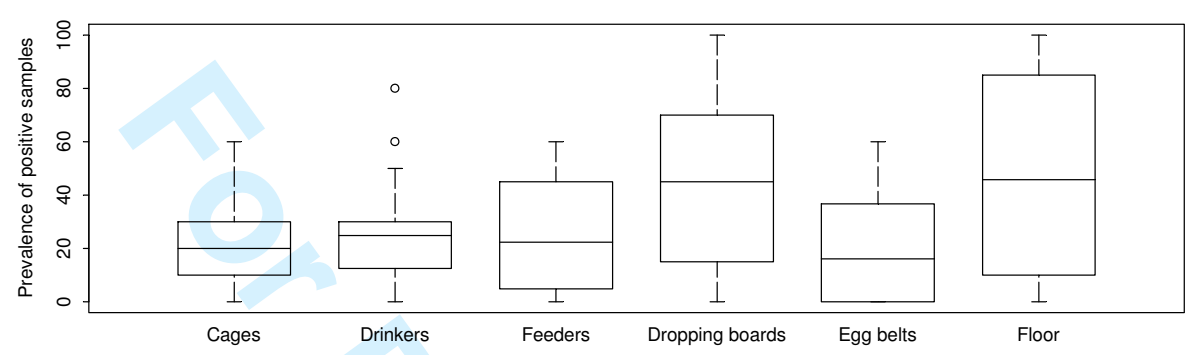

'F.G.Q. at G.O.'

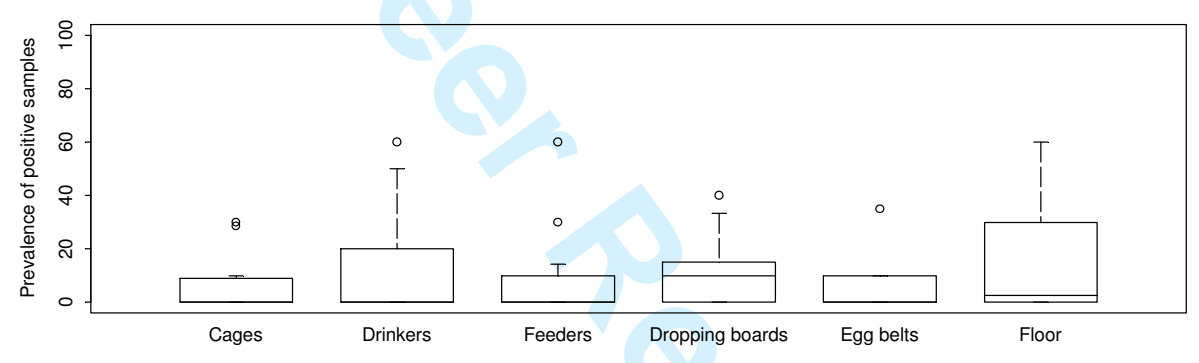

'Formalin 10\%'

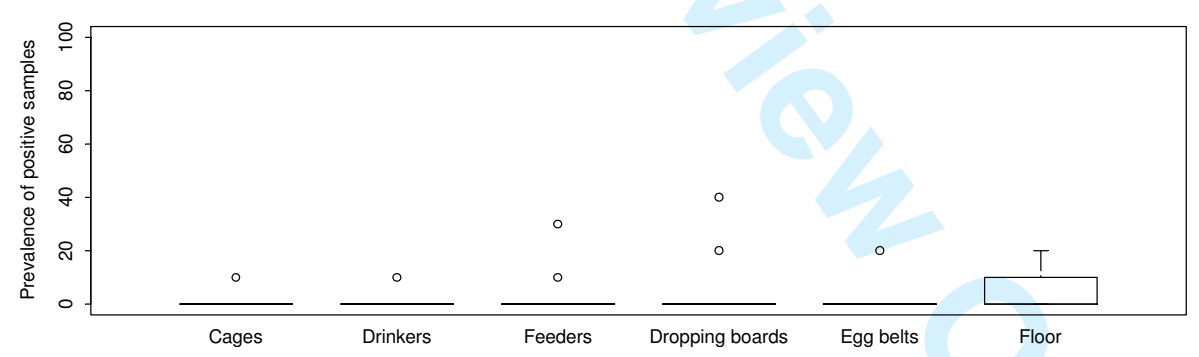


Figure 2. Results of the cleaning and disinfection of non-cage houses using an 'inhouse' disinfection method $(N=6)$, and formaldehyde/glutaraldehyde/quarternary ammonium (F.G.Q.) at General Orders (G.O) rate $(N=4)$.
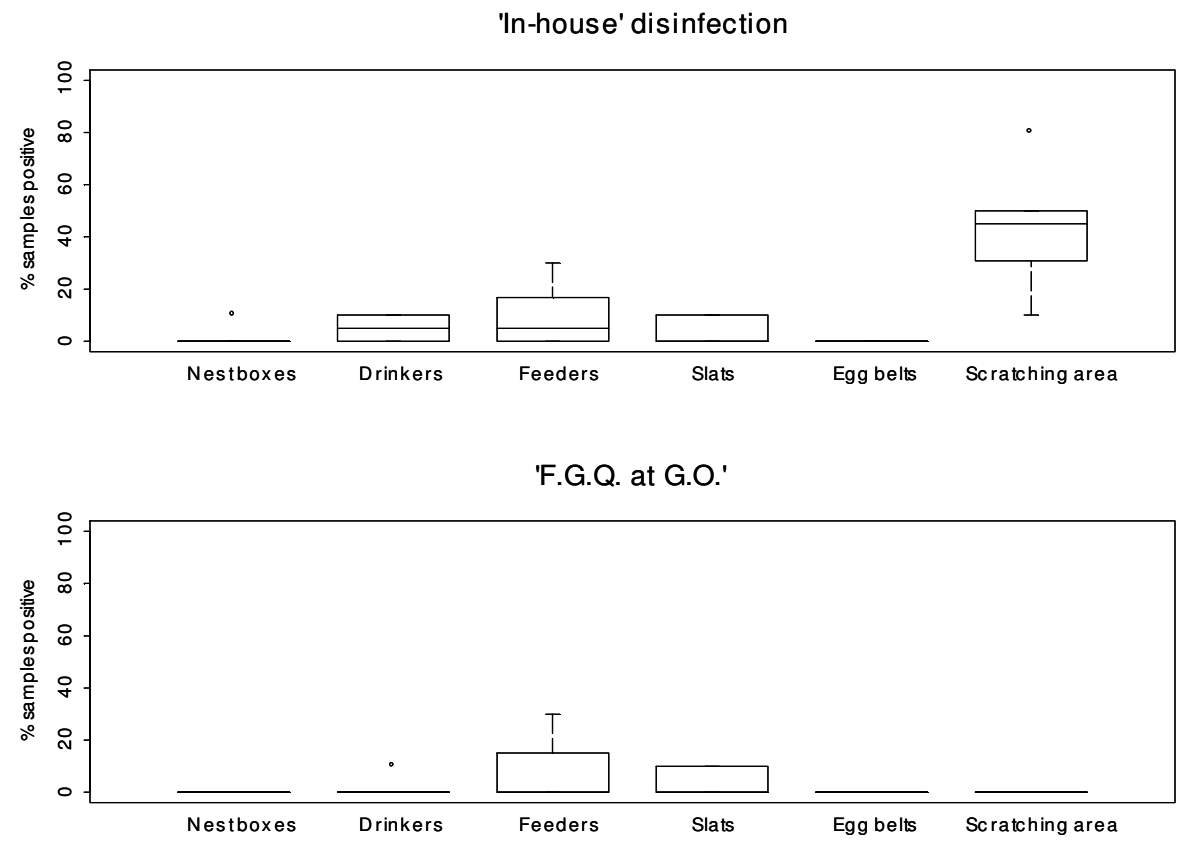
Figure 3. Change in the percent of positive samples collected from the flocks before and after disinfection using each of the three methods.
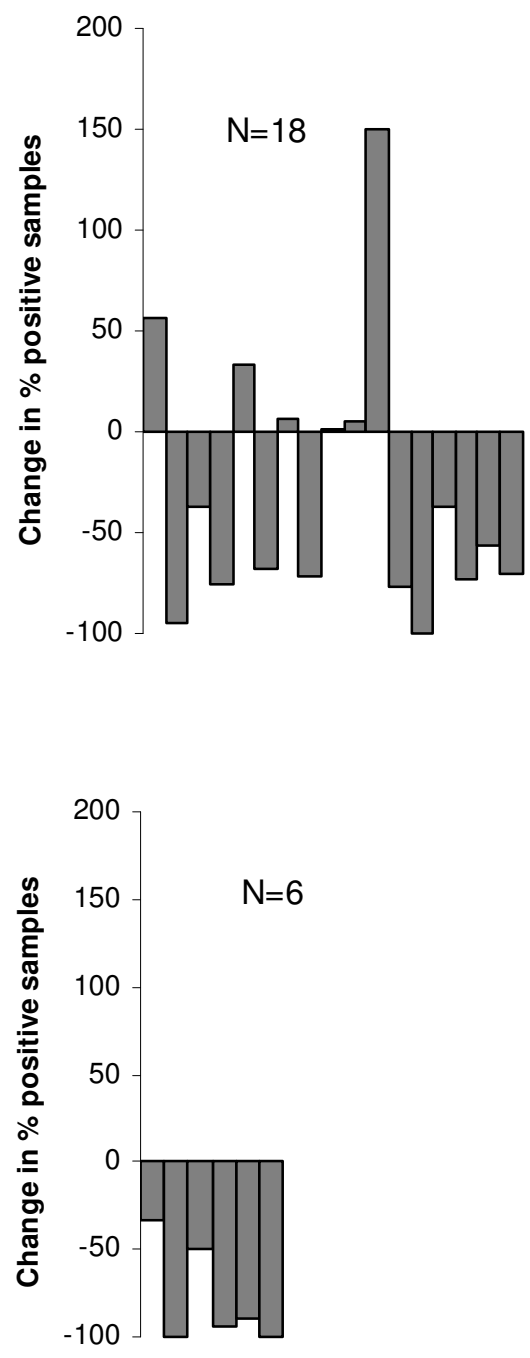

\section{Cage houses}

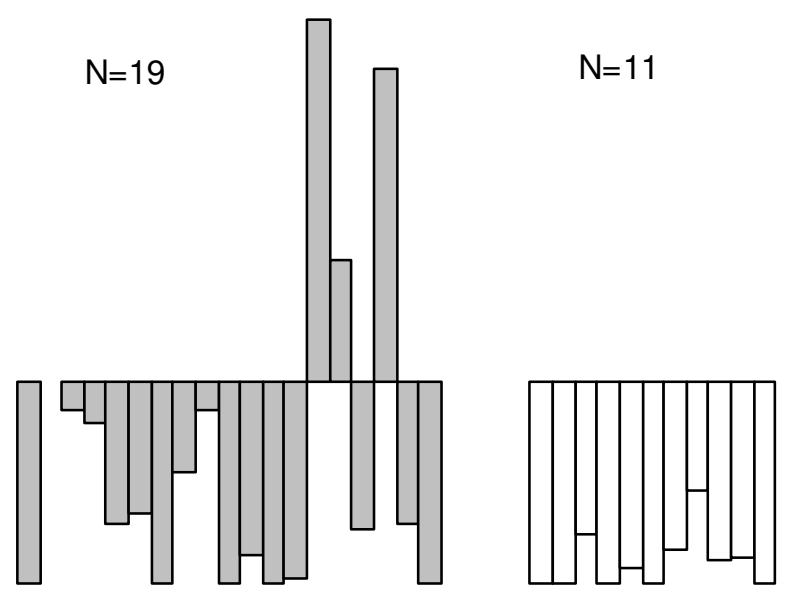

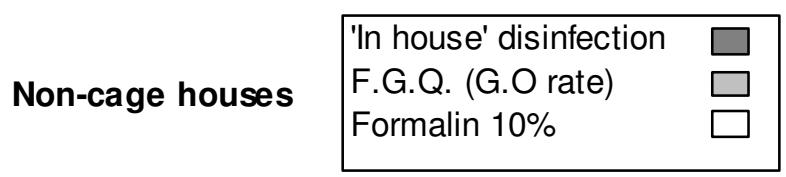

$\mathrm{N}=4$

$\mathrm{N}=2$
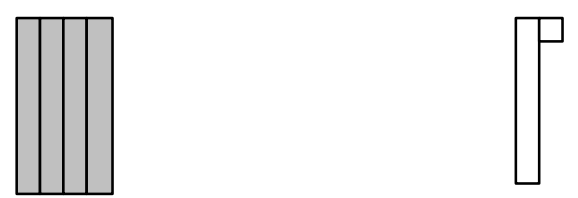